\title{
GAS SEPARATION PROPERTIES OF A THERMALLY STABLE AND CHEMICALLY RESISTANT POLYTRIAZOLE MEMBRANE
}

\author{
B. GEBBEN, M.H.V. MULDER and C.A. SMOLDERS \\ University of Twente, Department of Chemical Technology, P.O. Box 217, 7500 AE Enschede \\ (The Netherlands)
}

(Received November 4, 1987; accepted December 13, 1988)

\section{Summary}

The polymer poly (1,3-phenyl-1,4-phenyl)-4-phenyl-1,3,4-triazole has been investigated for its gas separation properties. This thermally stable and chemically resistant polymer can be processed into membranes by the phase-inversion technique because of its unexpectedly good solubility in formic acid. Homogeneous membranes have been tested with respect to their permeability for several gases, and the influence of time and temperature upon permeation has been investigated. The polymer shows reasonable permeabilities for several gases and excellent selectivities. After a conditioning time of several days in which the permeability of the faster-moving gases increases by a factor of about 2 , the permeation properties of the polymer remain constant for at least two months. A thermal treatment at $295^{\circ} \mathrm{C}$, just above the glass transition temperature, can reduce the conditioning time and can prevent the film from shrinkage at high permeation temperatures without affecting the permeation properties.

\section{Introduction}

Today, synthetic membranes are used in a wide range of application. However, most of these membranes show poor thermal and chemical resistance. Membranes with high stabilities could open up new fields of applications and prolong the lifetime of membranes already used for separation problems. A reasonably large research effort has been invested already in this field, and some thermally stable and chemically resistant polymer membranes have become commercially available; for example, membranes from polyimides, polybenzimidazoles and polybenzimidazolones [1-6] are now on the market.

The largest problem in the preparation of membranes from stable polymers is the difficulty in processing, due to the fact that these polymers have a low solubility and can often not be melted. These unfavourable properties, however, are linked to their high stability. Improvement of the processability, for example by introducing flexible units in the polymer backbone [7], inevitably leads to reduction in stability. The commercially available high temperature polymers often seem to show a compromise between processability and stability. 
In our effort to prepare stable polymer membranes, we have tried to obtain the maximum in stability without changing the chemical structure of the polymer. Generally speaking the structure should be all aromatic and/or heterocyclic without so-called "weak" spots such as hydrogen or oxygen, bonded to aliphatic groups, which can easily be attacked [7]. Poly (1,3-phenyl-1,4phenyl )-4-phenyl-1,3,4-triazole, which will be investigated in this paper, is an example of such a polymer. Due to its aromatic and heterocyclic character the polymer has an outstanding resistance against oxidative, hydrolytic or chlorine-mediated degradation, in combination with a high temperature resistance [8-10]. Furthermore, the polymer has the advantage that it is easily processable because of its surprisingly good solubility in formic acid.

In this paper the gas permeation properties of poly (1,3-phenyl-1,4-phenyl)4-phenyl-1,3,4-triazole will be discussed. The polymer was prepared by the method described by Holsten and Lilyquist [8] in a two-stage process by first preparing an aromatic polyhydrazide, followed by a reaction with aniline in polyphosphoric acid. A general reaction scheme is given in Fig. 1.

Homogeneous membranes of this polymer have been used for gas permea-

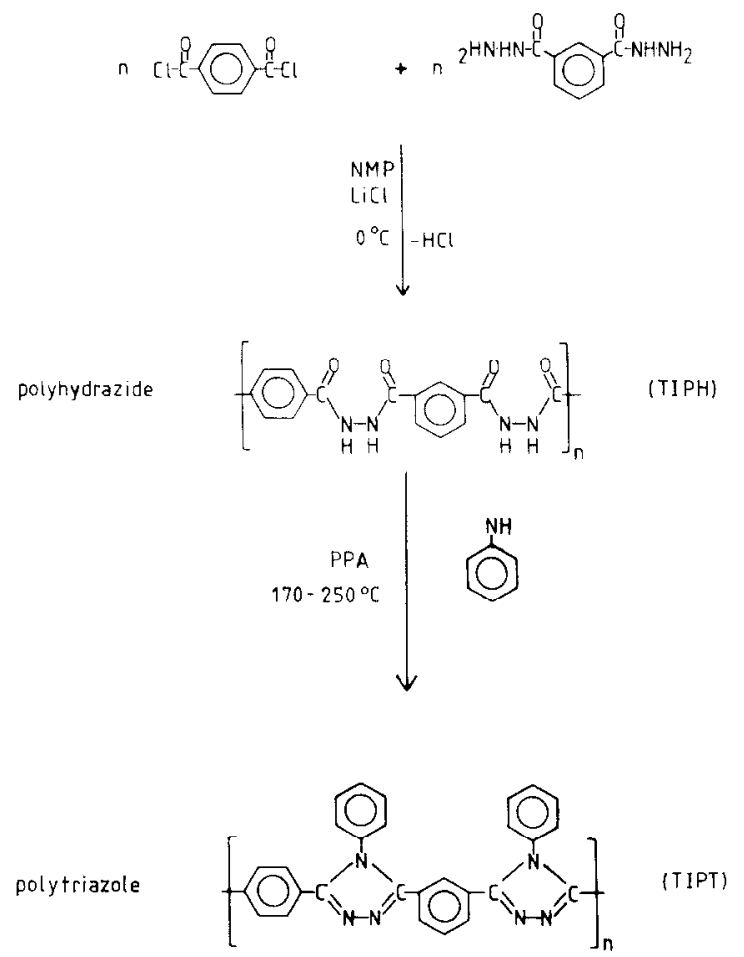

Fig. 1. Reaction scheme for the two-stage preparation of poly (1,3-phenyl-1,4-phenyl)-4-phenyl1,3,4-triazole. 
tion and gas separation experiments. Attention has been focussed on the separation of $\mathrm{CO}_{2} / \mathrm{CH}_{4}, \mathrm{O}_{2} / \mathrm{N}_{2}$ and $\mathrm{He} / \mathrm{N}_{2}$. The influence of time and temperature on membrane performance has been investigated. Because of the high temperature resistance of this polymer, the permeability properties have been measured at temperatures up to $200^{\circ} \mathrm{C}$.

\section{Experimental}

\section{Materials}

Terephthaloyl chloride was supplied by Merck and was recrystallized from hexane prior to use. Isophthaloyl hydrazide was prepared as described by Frazer and Wallenberger [11] from isophthalic acid methyl ester and hydrazine hydrate $(100 \%)$, both supplied by Merck. The isophthaloyl hydrazide was recrystallized from water, washed with methanol and dried before use. Aniline was supplied by Merck and was used as received. The solvents PPA (poly (phosphoric acid) ), NMP and formic acid (98\%) were supplied by Merck. The NMP was dried over molecular sieve $3 \AA$.

\section{Polymer preparation}

The prepolymer, poly (1,3-phenyl-1,4-phenyl)hydrazide, was prepared according to Frazer and Wallenberger [11] from terephthaloyl chloride and isophthaloyl hydrazide using a low temperature solution polycondensation reaction in NMP. Polymers were obtained with inherent viscosities of $1.4 \mathrm{dl} / \mathrm{g}$, measured in DMSO.

The polytriazole was prepared from the polyhydrazide by reacting this polymer with a mixture of aniline in PPA according to Holsten and Lilyquist [8]. Temperatures of $179-190^{\circ} \mathrm{C}$ and reaction times of $2-5$ days were used. Polymers were obtained with inherent viscosities of 1.2-1.4 dl/g, measured in formic acid.

The structural formula of the polymer could not be confirmed successfully using elemental analysis, infra-red analysis and thermogravimetric analysis. There is a possibility that some different structural elements are present in the chains, such as oxadiazole rings, open triazole rings or even some unreacted hydrazide groups. Elemental analysis gave: $\mathrm{N} 18.57 \%$ (theor. $19.2 \%$ ), C $72.88 \%$ (theor. $76.7 \%$ ), $\mathrm{H} 4.23 \%$ (theor. $4.1 \%$ ) residue $4.32 \%$ (theor. $0 \%$ ).

Using infra-red analysis, it can be observed that the carbonyl stretching band at $1650 \mathrm{~cm}^{-1}$, present in the initial polyhydrazide, has almost completely disappeared and that a $\mathrm{C}=\mathrm{N}$ band has appeared at $1580 \mathrm{~cm}^{-1}$. The thermogravimetric weight loss of the product recorded at temperatures between 200 and $400^{\circ} \mathrm{C}$, due to possible cyclisation of unreacted hydrazide groups [11], is less than $1 \%$, indicating that at least $90 \%$ of the initial hydrazide groups have reacted to either triazole or oxadiazole rings [8]. 


\section{Membrane preparation}

Solutions of the polytriazole were made by dissolving the polymer in formic acid at room temperatures. The concentrations varied from 15-25 wt.\% of polymer. The solutions were filtered through $5 \mu \mathrm{m}$ filters to remove inhomogeneities. Thin films were cast on a glass plate using a casting knife of $0.15 \mathrm{~mm}$ slit height. Homogeneous films were obtained by evaporating the solvent at $80^{\circ} \mathrm{C}$ in a nitrogen atmosphere. The films were removed from the glass plate with a little water. Finally, the membranes were dried in a vacuum oven at $150^{\circ} \mathrm{C}$ for at least $24 \mathrm{hr}$. The thickness of the films varied between 20 and 30 $\mu \mathrm{m}$.

\section{Chemical stability}

Small pieces of homogeneous films were exposed for a period of 30 days to the following conditions: hot air at $275^{\circ} \mathrm{C}$, boiling water, $\mathrm{pH}$ range of $1-13$ and a $10 \%$ solution of chlorine. The effect of these exposures upon the films was studied both visually and using infra-red analysis.

\section{Gas permeation experiments}

The flat sheet membranes were placed in Millipore dead-end filtration cells sealed with Viton rubber rings. The cells were put in an oven. The cells could

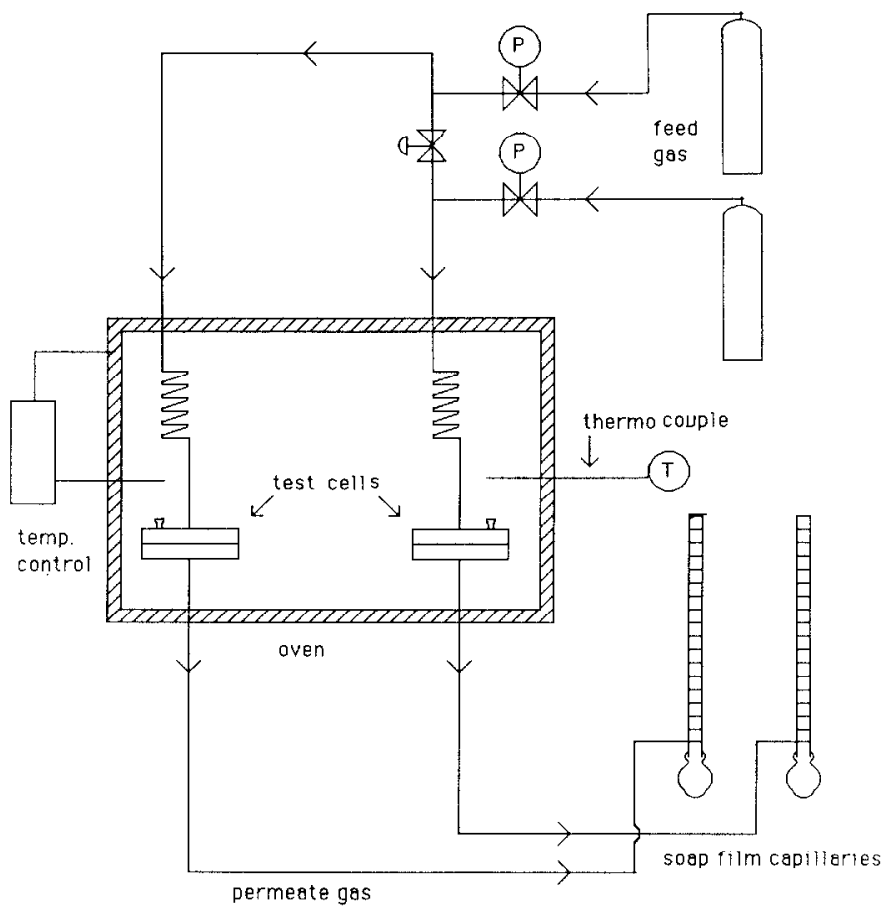

Fig. 2. Equipment for the permeation measurements of single gases. 
be fed with pure gases at pressures not exceeding 7 bar. The permeate flow was measured with soap film capillaries with capillary radius of $0.5 \mathrm{~mm}$. A schematic representation of the experimental set-up is given in Fig. 2.

The following pure gases were used: $\mathrm{O}_{2}, \mathrm{~N}_{2}, \mathrm{CO}_{2}, \mathrm{CH}_{4}$ and $\mathrm{He}$. The temperature of the oven could be raised to $200^{\circ} \mathrm{C}$, and its course was registered with a thermocouple.

The permeability, $P$, is calculated using the following formula:

$P_{i}=Q_{i} l /(A \Delta p)$

where $Q_{i}$ is the measured flow of gas $i\left(\mathrm{~cm}^{3} / \mathrm{sec}\right), l$ is the thickness of the film $(\mathrm{cm}), A$ is the membrane surface area $\left(\mathrm{cm}^{2}\right)$ and $\Delta p$ is the pressure difference across the membrane $(\mathrm{cmHg})$. The ideal selectivity, $\alpha_{\mathrm{id}}$, is defined as the ratio of the pure component permeabilities:

$\alpha_{\mathrm{id}}=P_{i} / P_{j}$

\section{$\mathrm{CO}_{2} / \mathrm{CH}_{4}$ separation measurements}

On a different type of equipment, membranes could be tested using gas mixtures of $\mathrm{CO}_{2}$ and $\mathrm{CH}_{4}$. A schematic representation of this installation is given in Fig. 3. The flux is determined by evacuating the downstream side of the membrane cell and accurately measuring the pressure increase with time in a calibrated volume. The permeability $P_{i}$ is calculated using the following formula:

$P_{i}=\left[(\Delta p / t) V x_{i, \mathrm{p}}\right] /\left(A p x_{i, \mathrm{f}}\right)$

where $\Delta p / t(\mathrm{cmHg} / \mathrm{sec})$ is the pressure increase per unit of time in the permeate chamber, $V$ the calibrated volume $\left(\mathrm{cm}^{3}\right), A$ the membrane surface area $\left(\mathrm{cm}^{2}\right), p$ the feed pressure $(\mathrm{cmHg})$ and $x_{i, \mathrm{f}}$ and $x_{i, \mathrm{p}}$ are the partial molarities of component $i$ in the feed and in the permeate, respectively.

The selectivity is determined using gas chromatography, and is defined as the quotient of the molar ratios in permeate and feed, respectively:

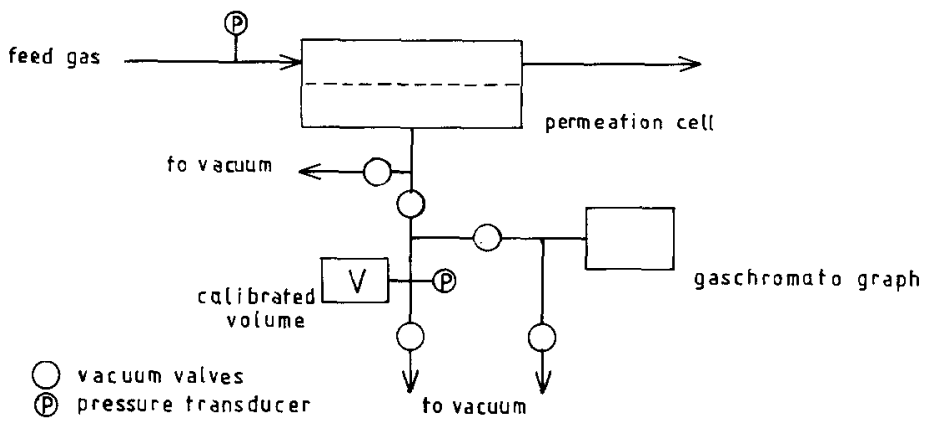

Fig. 3. Equipment for the separation measurements of $\mathrm{CO}_{2} / \mathrm{CH}_{4}$ gas mixtures. 
$\alpha=\left(x_{i} / x_{j}\right)_{\mathrm{p}} /\left(x_{i} / x_{j}\right)_{\mathrm{f}}$

The films were tested at 3 bar pressure difference, at room temperature and with gas mixtures containing $20 \%$ of $\mathrm{CO}_{2}$ and $80 \%$ of $\mathrm{CH}_{4}$ (molar ratios).

\section{Results and discussion}

\section{Influence of time}

In Fig. 4 the permeabilities of $\mathrm{He}, \mathrm{CO}_{2}, \mathrm{CH}_{4}$ and $\mathrm{N}_{2}$ are presented as a function of time using freshly prepared membranes. During the first days of the experiment, an increase in permeability by a factor of more than 2 is observed for the faster-permeating gases, $\mathrm{He}$ and $\mathrm{CO}_{2}$. The increase in permeability of the slowly permeating gases, $\mathrm{CH}_{4}$ and $\mathrm{N}_{2}$, is almost nil in a period of 14 days. After this initial conditioning period, the permeabilities become constant and remain constant for at least 2 months, as Fig. 5 illustrates; here the permeabilities for several pure gases are shown, measured with the same membrane at a temperature of $41^{\circ} \mathrm{C}$.

This initial increase in permeability can be explained either by a slow replacement of solvent or water molecules present in the initial film by the fastpermeating gas molecules or by a relaxation phenomenon of the polymer, or a combination of both. The influence of thermal treatment at a high temperature on this initial behaviour of the membrane permeabilities will be discussed below.

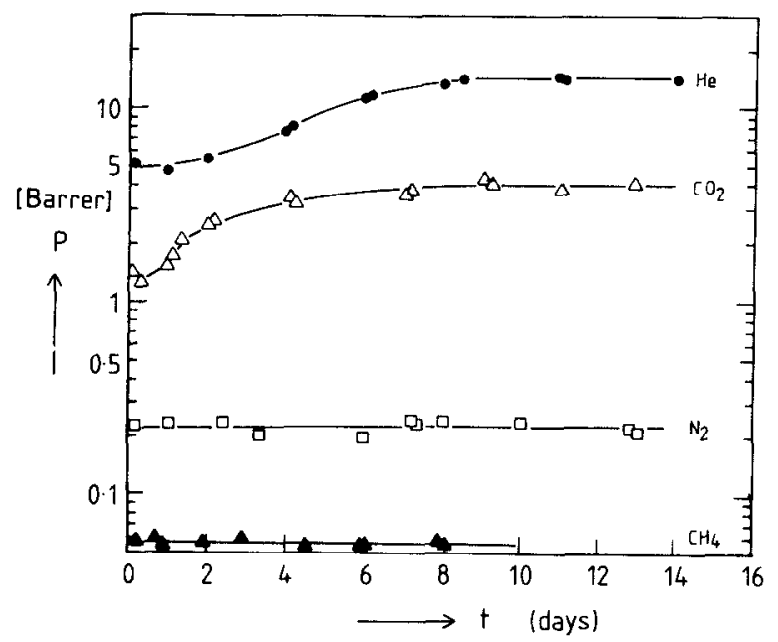

Fig. 4. Pure gas permeabilities for several gases, each measured with a freshly prepared polytriazole membrane as a function of time, at $50^{\circ} \mathrm{C}$ and 6 bar pressure difference. 1 barrer $=10^{-10} \mathrm{~cm}^{3}$ (STP) $-\mathrm{cm}-\mathrm{cm}^{-2}-\mathrm{sec}^{-1}-\mathrm{cmHg}^{-1}$. 


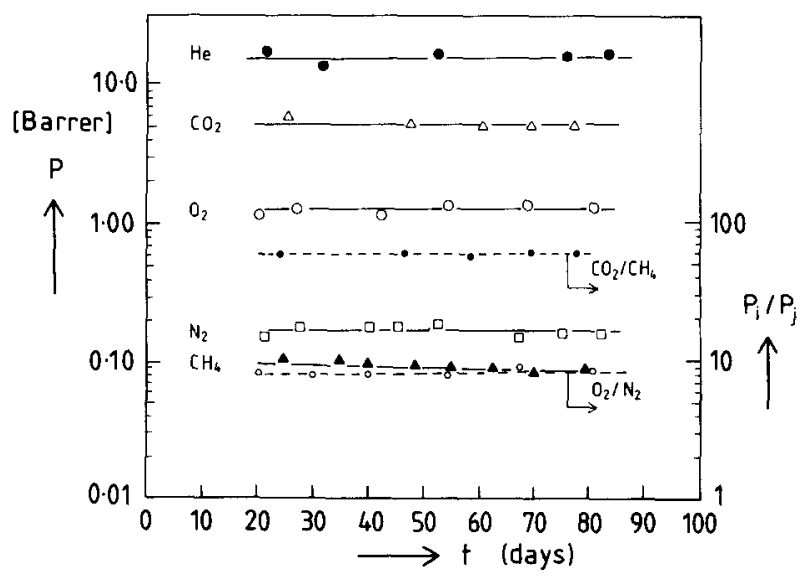

Fig. 5. Pure gas permeabilities for several gases, all measured with the same membrane after a conditioning period of fourteen days as a function of time, at $41^{\circ} \mathrm{C}$ and 6 bar pressure difference.

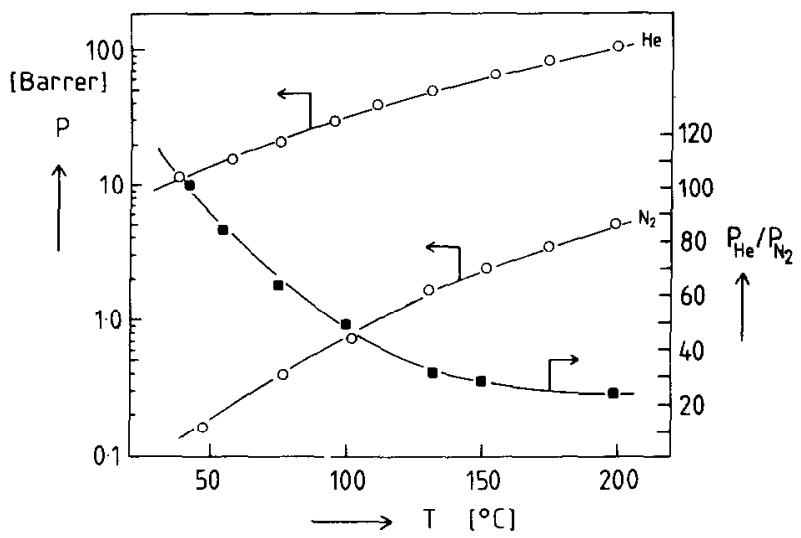

Fig. 6. He and $\mathrm{N}_{2}$ permeabilities and ideal selectivity measured with a conditioned polytriazole membrane as a function of temperature.

\section{Influence of temperature}

Figure 6 shows the influence of the temperature on the permeabilities and the ideal selectivity of $\mathrm{He}$ and $\mathrm{N}_{2}$. Increasing the temperatures up to $200^{\circ} \mathrm{C}$ leads to a considerable increase in the permeability and a decrease in the ideal selectivity from about 120 at room temperature to about 25 at $200^{\circ} \mathrm{C}$. The same type of behaviour for $\mathrm{O}_{2}$ and $\mathrm{N}_{2}$ is presented in Fig. 7. The ideal selectivity for the $\mathrm{O}_{2} / \mathrm{N}_{2}$ separation at room temperature, being about 10 , is rather high compared with other polymers [16], but it decreases to about 3 at $200^{\circ} \mathrm{C}$, which is still reasonable considering the higher permeabilities.

From the permeation vs. temperature data Arrhenius plots can be derived. In Fig. 8 the Arrhenius plots are presented, showing straight lines with high 


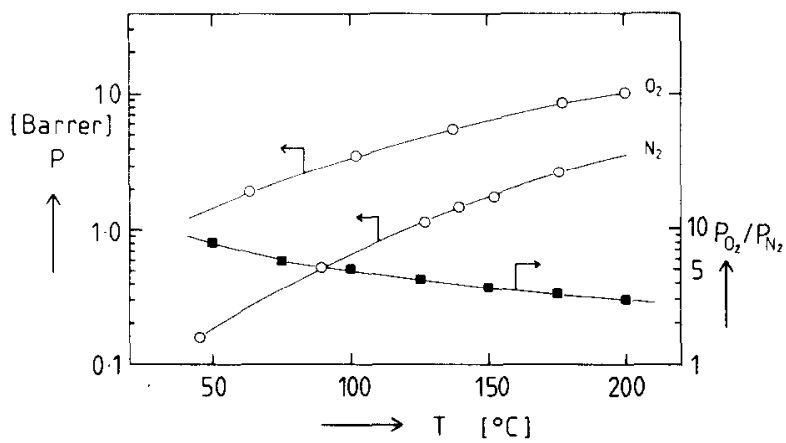

Fig. 7. $\mathrm{O}_{2}$ and $\mathrm{N}_{2}$ permeabilities and ideal selectivity measured with a conditioned polytriazole membrane as a function of temperature.

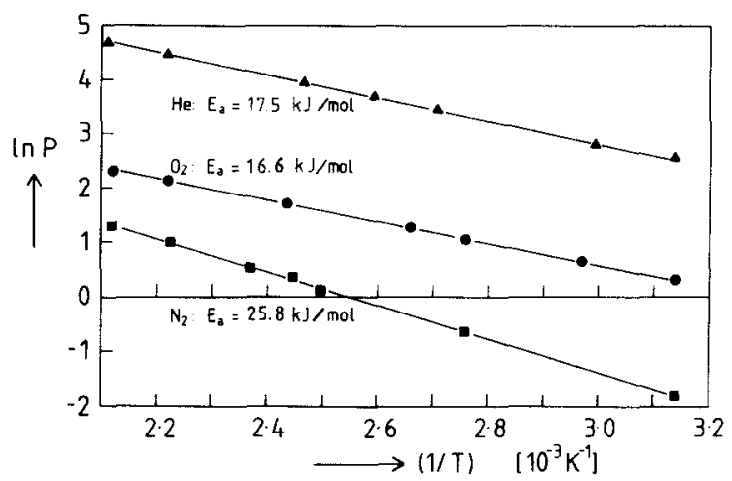

Fig. 8. Arrhenius plots for $\mathrm{He}, \mathrm{O}_{2}$ and $\mathrm{N}_{2}$ permeabilities measured with conditioned polytriazole membranes.

correlation coefficients for the three gases studied and indicating that the pure gas permeation of $\mathrm{He}, \mathrm{O}_{2}$ and $\mathrm{N}_{2}$ follows an Arrhenius behaviour. 'The energies of activation for the $\mathrm{He}, \mathrm{O}_{2}$ and $\mathrm{N}_{2}$ permeation calculated from the slopes are $17.5,16.6$ and $25.8 \mathrm{~kJ} / \mathrm{mol}$, respectively. These values are in the same order of magnitude as the energies of activation for diffusion in amorphous polymers [12].

\section{$\mathrm{CO}_{2} / \mathrm{CH}_{4}$ separation}

Figure 9 gives a selectivity-permeability plot for homogeneous films of the following commercial polymers: polysulfone (PSF) (P3500, Udel), polyethersulfone (PES) (Victrex, ICI), poly (phenylene oxide (PPO) (General Electric) and poly (ether imide (PEI) (Ultem, General Electric), all measured using the same $\mathrm{CO}_{2} / \mathrm{CH}_{4}$-separation equipment and under the same conditions [13]. The values for Kapton polyimide are obtained from the literature [14]. The results for the polytriazole films are presented in the shaded rectangle. 


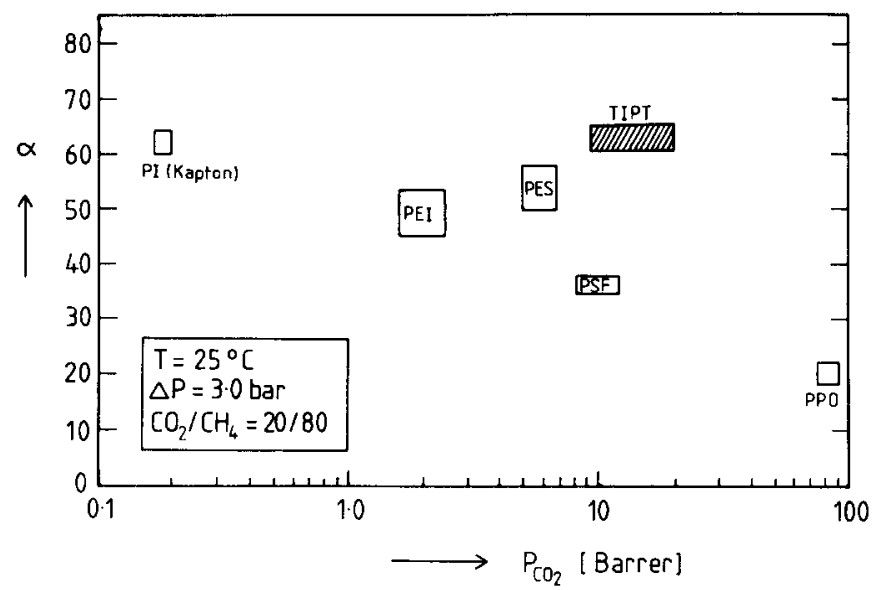

Fig. 9. Permeability-selectivity plot for the separation of $\mathrm{CO}_{2} / \mathrm{CH}_{4}$ mixtures (20/80) measured with flat sheet homogeneous membranes for several different polymers, at $25^{\circ} \mathrm{C}$ and 3.0 bar pressure difference.

Compared with the above mentioned polymers, the polytriazole membrane possesses an excellent selectivity and a reasonable $\mathrm{CO}_{2}$ permeability. Especially if the $\mathrm{CO}_{2}$ permeability is compared with that of Kapton, which is also a thermally stable and chemically resistant polymer, the difference is striking. Although the reproducibility of the selectivity was good, the measured permeabilities sometimes differed by a factor of 2 . These variations might be caused by an effect of $\mathrm{CO}_{2}$ conditioning, since the films that had first been tested on the single permeability equipment showed higher $\mathrm{CO}_{2}$ gas fluxes, but freshly prepared films showed lower fluxes. Beside this conditioning reproducibility of the permeability, it can be observed that the measured $\mathrm{CO}_{2}$ permeabilities using this $\mathrm{CO}_{2} / \mathrm{CH}_{4}$ separation equipment are at least a factor of 2 higher than the permeabilities measured by using the single gas permeation equipment. We believe this to be caused by the difference in the permeate pressure and/or the experimental technique of measuring the permeate fluxes.

\section{Thermal treatment of the films}

After permeation measurements at $200^{\circ} \mathrm{C}$ some shrinkage of the membranes was noticed, which sometimes led to leakage of the membranes at the edges. In order to prevent this the films were pre-shrunk by a thermal treatment of 1 $\mathrm{hr}$ at $295^{\circ} \mathrm{C}$ as advocated by Lilyquist and Holsten [9], who performed such a treatment on their polytriazole fibres.

Another reason for thermal treatment is the completion of possibly unfinished ring-closure reactions. Since we are dealing with a thermally stable and chemically resistant polymer, it is important for the final stability that all the 
hydrazide groups present in the initial polyhydrazide should have been closed to a ring, either a triazole or an oxadiazole ring. It is questionable, however, whether such a short thermal treatment is sufficient to finish these very last ring closures, considering the prolonged heating times and elevated temperatures reported in the literature for completion of the polyhydrazide conversion $[11,15]$.

In Table 1 the effects of the thermal treatment on some film properties are represented. It is very striking to notice the marked shrinkage of the film, by about $20 \%$. This shrinkage, however, does not seem to affect the gas permeability values. Almost the same values are obtained for membranes with or without a thermal treatment. The effect of the heat treatment on the initial permeability values is illustrated in Fig. 10, where it can be seen that membranes which have had the thermal treatment show a considerably shorter conditioning time and a final constant permeability value which is equal to the value for the conditioned membranes without the heat treatment. The question now is raised about the nature of both the conditioning process and the thermal treatment.

In Fig. 11, DSC curves of the film before (curve b) and after (curve c) the thermal treatment and after a conditioning experiment with $\mathrm{CO}_{2}$ gas permeation (curve d) are represented. Comparison of curves $c$ and d shows clearly that there is a difference between these two treatments. Compared with the thermogram of a polytriazole powder (curve a, the washed and dried reaction product) the thermograms of the films are different in two respects. First, the glass transition temperatures of the films $\left(270^{\circ} \mathrm{C}\right)$ are about $25^{\circ} \mathrm{C}$ lower than

\section{TABLE 1}

Properties of a homogeneous polytriazole film before and after heat treatment at $295^{\circ} \mathrm{C}$ for $1 \mathrm{hr}$

\begin{tabular}{lcc}
\hline Property & Before & After \\
\hline Volume $^{\mathrm{a}}$ & $V_{0}$ & $0.8 V_{0} \pm 0.08 V_{0}$ \\
Weight $^{\mathrm{b}}$ & $w_{0}$ & $0.9 w_{0} \pm 0.04 w_{0}$ \\
${\text { Density }\left(\mathrm{g} / \mathrm{cm}^{-3}\right)^{\mathrm{c}}}^{\mathrm{d}}$ & 1.243 & 1.234 \\
$T_{\mathrm{g}}\left({ }^{\circ} \mathrm{C}\right)^{\mathrm{d}}$ & 270.4 & 275.6 \\
& & \\
$P(\mathrm{He})^{\mathrm{e}}$ & 14.0 & 14.5 barrer \\
$P\left(\mathrm{~N}_{2}\right)$ & 0.2 & 0.2 barrer \\
$P\left(\mathrm{CO}_{2}\right)^{\mathrm{r}}$ & & \\
$\alpha\left(\mathrm{CO}_{2} / \mathrm{CH}_{4}\right)$ & 8.9 & 9.2 barrer \\
\hline
\end{tabular}

${ }^{a}$ Determined by measuring the dimensions.

${ }^{b}$ Determined by thermogravimetric analysis.

'Determined using a density gradient column of tetrachloromethane and 2-ethyl-2-methylpentanol.

${ }^{\mathrm{d}}$ Determined by DSC at $20^{\circ} \mathrm{C} / \mathrm{min}$.

${ }^{e}$ Determined on the gas permeation equipment at $50^{\circ} \mathrm{C}$ and 6 bar after conditioning.

Determined on the $\mathrm{CO}_{2} / \mathrm{CH}_{4}$ separation equipment at 3 bar pressure difference. 


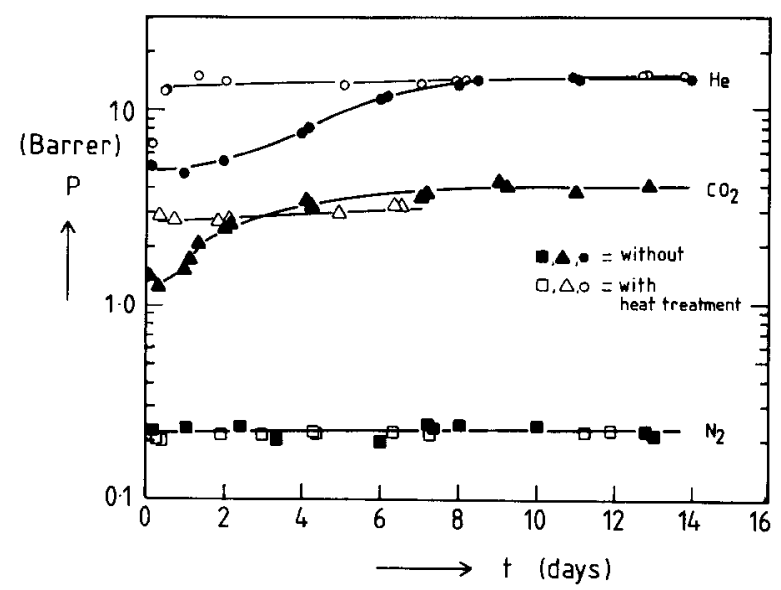

Fig. 10. Pure gas permeabilities for several gases, each measured with a freshly prepared polytriazole membrane with and without a thermal treatment at $295^{\circ} \mathrm{C}$ as a function of permeation time, at $50^{\circ} \mathrm{C}$ and 6 bar pressure difference.

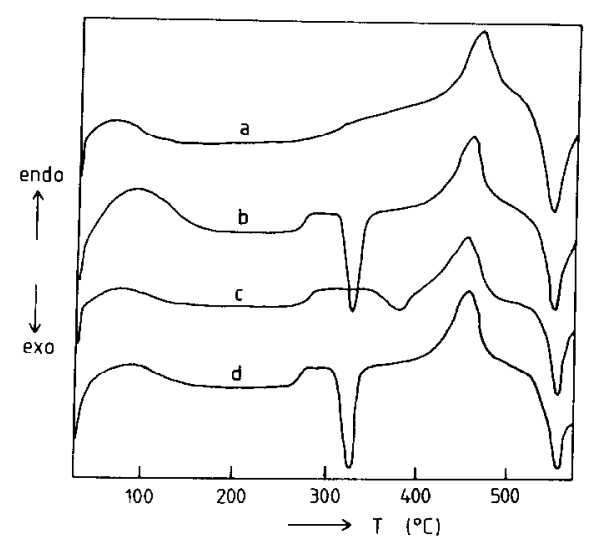

Fig. 11. DSC thermograms for the polytriazole powder (a), for a homogeneous polytriazole film before (b) and after (c) heat treatment at $295^{\circ} \mathrm{C}$, and for a homogeneous film after $\mathrm{CO}_{2}$ permeation during 14 days $(\mathrm{d})$.

the $T_{\mathrm{g}}$ for the powder $\left(295^{\circ} \mathrm{C}\right)$, and second, the non-heat-treated film exhibits a sharp exothermic peak just after the glass transition, which is not observed at all in the powder thermogram. This DSC behaviour of the film is typical for semi-crystalline polymers which show a so-called cold crystallisation phenomenon just after the glass transition temperature. After the thermal treatment of the film, the sharp exotherm has shifted to higher temperatures and has decreased in size. An explanation for this phenomenon might be that, during the thermal treatment of the polymer film, there has been some crystalline ordering in the polymer which is responsible for the decrease and shift of the 
TABLE 2

Effect on a homogeneous polytriazole film after exposure to several severely aggressive treatments

\begin{tabular}{lll}
\hline Treatment & \multicolumn{2}{l}{ Effect } \\
\cline { 2 - 3 } & visual & IR \\
\hline Boiling water & none & none \\
$275^{\circ} \mathrm{C}$ & none & none \\
$\mathrm{pH}$ range $1-13$ & none & none \\
Chlorine solution $(10 \%)$ & none & none \\
Conc. $\mathrm{HCl}$ & brittle & bigger $\mathrm{C}=0$ peak at $1680 \mathrm{~cm}^{-1}$ \\
\hline
\end{tabular}

exothermic peak during the subsequent DSC run. In this context the endothermic peak starting at about $400^{\circ} \mathrm{C}$, which is present in all the DSC curves, possibly represents the crystalline melting. The powder does not show the exothermic peak when it already possesses crystallinity. With X-ray diffraction (WAXS, wide angle X-ray scattering) some small degree of crystallinity or ordering could indeed be observed in the polytriazole powder.

While a thermal treatment probably causes some crystallinity in the polymer, the $\mathrm{CO}_{2}$ permeation obviously does not. It is not unreasonable to assume that the presence of traces of solvent and/or water plays some role in these phenomena. More research, however, is needed to understand fully the exact nature of this thermal treatment effect and the nature of the conditioning process.

\section{Chemical stability}

Table 2 shows the results from the chemical stability test performed with homogeneous films of the polytriazole studied. After a period of 30 days the films are only affected by the concentrated hydrochloric acid, which clearly makes them brittle.

\section{Conclusion}

The investigated polytriazole polymer combines good thermal stability and chemical resistance with processability. This polytriazole seems to be a promising polymer for gas separation, not only at ambient temperature but also at elevated temperatures. High separation factors were found for $\mathrm{CO}_{2} / \mathrm{CH}_{4}$ and for $\mathrm{O}_{2} / \mathrm{N}_{2}$ separation, with reasonable permeabilities compared to other thermally stable polymers. Increase in the temperature at which the permeation experiments are performed leads to an increase in permeability and a decrease in selectivity. The permeabilities of the pure gases follow Arrhenius behaviour.

Newly prepared membranes show an initial increase in membrane performance when they are permeated with $\mathrm{CO}_{2}$ and $\mathrm{He}$ in a dead-end permeation cell 
with atmospheric pressure at the permeate side. After this initial conditioning period, the performance of the membranes can be maintained for a period of at least 2 months. An additional heat treatment for newly prepared membranes of $1 \mathrm{hr}$ at $295^{\circ} \mathrm{C}$ makes the membranes shrink by about $20 \%$ and shortens the conditioning time, but does not affect their final separation properties.

\section{References}

1 H. Strathmann, Asymmetric polyimide membranes for filtrations of non-aqueous solutions, Desalination, 26 (1978) 85.

2 A. Iwama and Y. Kazuse, New polyimide ultrafiltration membranes for organic use, J. Membrane Sci., 11 (1982) 297.

3 M.N. Surbolouki, Properties of asymmetric polyimide ultrafiltration membranes. I. Pore size and morphology characterization, J. Appl. Polym. Sci., 29 (1984) 743.

4 F.S. Model, H.J. Jones and J.E. Proust, PBI membranes for reverse osmosis, in: S. Sourirajan (Ed.), Reverse Osmosis and Synthetic Membranes, National Research Council of Canada, 1977.

5 L.C. Sawyer and R.S. Jones, Observations on the structure of the first generation polybenzimidazole reverse osmosis membranes, J. Membrane Sci., 20 (1984) 147.

6 R.L. Goldsmith, B.A. Wechsler and S. Hara, Development of PBIL low pressure brackishwater reverse osmosis membranes, Desalination, 22 (1977) 311.

7 P.E. Cassidy, Thermally Stable Polymers: Synthesis and Properties, Marcel Dekker, New York, NY, 1980.

8 J.R. Holsten and R.M. Lilyquist, Aromatic poly (phenylene-4-phenyl-1,2,4-triazoles), J. Polym. Sci., Part A, A3 (1965) 3905.

9 R.M. Lilyquist and J.R. Holsten, Poly (phenylenetriazoles): New thermally stable fibers. J. Polym. Sci., Part C, C19 (1967) 77.

10 U.S. Patent 3,318,728, to Monsanto Co, 1967.

11 A.H. Frazer and F.T. Wallenberger, Aliphatic polyhydrazides: A new low temperature solution polymerization, J. Polym. Sci., Part A, A2 (1964) 1137.

12 J. Crank and G.S. Park (Eds.), Diffusion in Polymers, Academic Press, London, 1968.

13 P. Kamps, Internal report, University of Twente, The Netherlands, 1987.

14 R.T. Chern, W.J. Koros, H.B. Hopfenberg and V.T. Stannett, Material selection for membrane-based gas separations, in: D.R. Lloyd (Ed.), Materials Science of Synthetic Polymer Membranes, ACS Symp. Ser., No. 269, American Chemical Society, Washington, DC, 1985, p. 25.

15 B. Gebben, M.H.V. Mulder and C.A. Smolders, Cyclodehydration reaction of polyhydrazides. I. Kinetic parameters obtained with nonisothermal thermogravimetry, J. Polym. Sci., Polym. Chem. Ed., 26 (1988) 1743.

16 O.J. Sweeting (Ed.), The Science and Technology of Polymer Films, Vol. 2, Wiley, New York, NY. 1971. 